\title{
РЕПРОДУКТИВНЫЕ НАМЕРЕНИЯ РОССИЯН: МОТИВАЦИЯ И СДЕРЖИВАЮЩИЕ ФАКТОРЫ
}

\author{
ТАТЬЯНА ГуДКОВА
}

\begin{abstract}
В статье рассматривается роль различных факторов, которые влияют на принятие решения о рождении ребенка. Основное внимание уделяется мотивированным решениям иметь или не иметь (еще одного) ребенка и сочиально-экономическим и социально-психологическим сдерживающим факторам, влияющим на откладывание рождения детей.
\end{abstract}

Полученные количественные и качественные оченки свидетельствуют о том, что социальная норма относительно «правильного» размера российской семьи остается достаточно стабильной: в среднем женщины и мужчины желают иметь двоих детей. Среднее ожидаемое число детей у российских женщин и мужчин тоже остается на достаточно высоком уровне, близком к двум. При этом данные фокус-групп выявили увеличивающуюся в обществе поляризацию между теми, кто намерен иметь только одного ребенка, и теми, кто хочет и планирует иметь больщую (многодетную) семью.

В исследовании выявлены главные мотивы для рождения большего числа детей - стремление родителей к тому, чтобы их дети не чувствовали себя одинокими и научились заботиться о младиих, что обеспечивает, по мнению родителей, больше гарантий получения поддержки от детей в старости. Не менее важными мотивами являются намерение респондентов укрепить семью и желание со стороны их супругов/партнеров иметь еще одного ребенка. Материальные и социальные возможности семьи и поддержка со стороны государства также играют немаловажную роль при планировании рождения еще одного ребенка (особенно третьего). На формирование репродуктивных намерений российских женщин и мужчин оказывают влияние и сочиальнопсихологические факторы: неуверенность в прочности брака/партнерства либо неготовность супругов/партнеров (морально, физически либо материально) к появлению (еще одного) ребенка в семье являются значимыми факторами откладывания рождений.

Ключевые слова: рождаемость, репродуктивные намерения, ожидаемое число детей, желаемое число детей, многодетность, мотивы рождения, откладывание рождений, Россия.

\section{ВВЕДЕНИЕ}

Неослабевающий интерес демографов к изучению тенденций рождаемости едва ли не в первую очередь мотивирован их стремлением научиться предсказывать изменение этих тенденций в будущем, прогнозировать рождаемость. Именно заинтересованность в таком прогнозе породила целое направление демографических исследований, активно развивающееся с середины прошлого века - изучение репродуктивных намерений женщин путем их прямого опроса. Как писали пионеры этого направления исследований американские демографы Норман Райдер и Чарльз Уэстоф, «метод был рискованным по своей простоте: попросить каждую женщину сделать собственный прогноз ее будущей рождаемости. Хотя в индивидуальных оценках, конечно, ожидались ошибки, можно было надеяться, что они уравновесят друг друга и что сводные прогнозы окажутся, в среднем, приемлемыми» (Райдер, Уэстоф, 1971: 67).

ТАТЬЯНА БОРИСОВНА ГУДКОВА (tbgudkova@hse.ru), НАЦИОНАЛЬНЫЙ ИССЛЕДОВАТЕЛЬСКИЙ УНИВЕРСИТЕТ «ВЫСШАЯ ШКОЛА ЭКОНОМИКИ», РОССИЯ.

ИССЛЕДОВАНИЕ ОСУЩЕСТВЛЕНО В РАМКАХ ПРОГРАММЫ ФУНДАМЕНТАЛЬНЫХ ИССЛЕДОВАНИЙ НИУ ВШЭ В 2019 Г.

СТАТЬЯ ПОСТУПИЛА В РЕДАКЦИЮ В НОЯБРЕ 2019 Г. 
Несмотря на простоту, метод оказался достаточно эффективным. Тема репродуктивных предпочтений населения стала своего рода «золотым стандартом» в исследованиях рождаемости (Coombs 1979; Westoff 1990; Bongaarts 2001; Morgan 2001; Voas 2003). Изучение репродуктивных намерений быстро получило широкое распространение, в том числе и в СССР, где, начиная с 1960-х гг., было проведено большое количество таких исследований, среди них такое крупное, как опрос 300000 женщин, проведенный в 1972 г. Отделом демографии НИИ ЦСУ СССР (Белова 1975: 44-48).

Традиция изучения репродуктивных намерений получила развитие в постсоветской России. Репродуктивные установки изучались в рамках ежегодного мониторинга (с 1991 по 2000 гг., за исключением 1993 г.) Всероссийского центра изучения общественного мнения (ВЦИОМ) (Бодрова 1997, 1999). Вопросы о желаемом и ожидаемом числе детей были включены в программу микропереписи населения 1994 года (Борисов 1997), которая, по мнению исследователей, после опроса 1972 г. вплоть до 2000-х гг. была «единственным репрезентативным для России исследованием репродуктивных ориентаций» (Архангельский 2006). С 2004 года изучение репродуктивных установок россиян проводилось преимущественно на данных трех волн обследования «Родители и дети, мужчины и женщины в семье и обществе» (РиДМиЖ) (Головляницина 2007; Захаров 2012, Тындик 2012), которое позволило изучить также взаимосвязь репродуктивных намерений и последующего поведения на панельных данных (Синявская, Тындик 2009).

Со времен Уэстофа и Райдера решение о рождении ребенка принято называть репродуктивным намерением (Westoff, Ryder 1977; Morgan 1985). Многие исследователи определяют репродуктивные намерения в качестве опосредующей детерминанты фактического поведения рождаемости (там же; Liefbroer 2009; Philipov 2009; Morgan, Rackin 2010; Iacovou, Tavares 2011). В научной литературе выделяют два основных вида репродуктивных намерений: желаемое число детей или желаемый размер семьи, и намерения в отношении очередного ребенка, т.е. намерения иметь (еще одного) ребенка вообще или в течение какого-то определенного времени (Balbo, Billari, Mills 2013). Первый вид репродуктивных намерений является достаточно слабым предиктором реальной рождаемости (van Peer, Rabušic 2008), так как предпочтения в отношении желаемого числа детей могут меняться в течение жизни (как в положительную, так и в отрицательную стороны). Второй же вид считается более стабильным и надежным (Philipov 2009), особенно в случае указания временных сроков (например, в течение ближайших двух или трех лет) (Balbo, Billari, Mills 2013).

Ряд исследователей также подчеркивают значимую роль в формировании репродуктивных намерений и их реализации господствующих в обществе норм, относительно размера семьи (сколько детей желательно иметь) (Caldwell 1982; Rindfuss, Morgan, Swicegood 1988; Kohler 2001). Так, на протяжении последних десятилетий социальной нормой в европейских странах, в том числе и в России, является модель двухдетной семьи (Sobotka, Beaujouan 2014; Захаров, Чурилова, Агаджанян 2016).

Репродуктивные намерения включают в себя не только число детей, но и время их появления на свет. В них находит отражение «постарение» возрастной модели рождаемости, начавшееся на Западе в 70-е годы прошлого века, а позднее 
распространившееся и на Россию. Тема более позднего, отложенного родительства привлекает внимание не только исследователей, но и политических деятелей и общественного мнения. Дебаты имеют разные ракурсы, отражающие как преимущества, так и недостатки позднего родительства. Некоторые исследователи рассматривают его как положительный опыт: зрелые родители могут обеспечить детям более высокий уровень жизни и более стабильные семейные отношения, улучшая их будущие жизненные шансы (McLanahan 2004), эволюция возрастной модели рождаемости рассматривается как закономерный процесс (Захаров, Вишневский, Сакевич 2006; Фрейка, Захаров 2014). Позднее родительство связано с меньшей вероятностью рождения детей одинокой матерью, живущей без партнера (Schmidt et al. 2011), и с более низкой долей незапланированных беременностей и рождений (Mosher, Jones, Abma 2012). У самих матерей поздний возраст при рождении ребенка ассоциируется с хорошим здоровьем и долголетием (Jaffe et al. 2015). В то же время, отложенное родительство зачастую изображается как опасное, потенциально угрожающее здоровью матери или ребенка, либо как основная причина вынужденной бездетности (Selvaratnam 2014) и демографического кризиса (Антонов 2009). Последние опасения все чаще отражаются в дискуссиях о возрастных ограничениях в политических инициативах, направленных на информирование женщин (и мужчин) о репродуктивном старении и стимулированию их к рождению детей в более молодом возрасте.

\section{МЕТОДОЛОГИЯ ИССЛЕДОВАНИЯ}

Репродуктивные намерения россиян не остаются неизменными. Представленные в рамках настоящего исследования результаты получены при анализе данных двух относительно недавних обследований: «Выборочного наблюдения репродуктивных планов населения» (РПН) 2012 и 2017 г. (Выборочное наблюдение... 2012; 2017). Обследования РПН-2012 и РПН-2017, проводившиеся Росстатом во всех субъектах Российской Федерации, являются репрезентативными. Размер выборки РПН-2012 составляет 10 тыс. респондентов (женщин в возрасте 18-44 года и мужчин в возрасте 18-60 лет), РПН-2017 - 15 тыс. респондентов (каждый респондент представляет одно домохозяйство). Изучение различных аспектов репродуктивного поведения на данных обследования проводилось и ранее (Захаров, Чурилова, Агаджанян 2016; Архангельский 2018; Землянова, Чумарина 2018), однако в отличие от предшествующих исследований, в нашей работе были использованы не только данные итоговых таблиц, но и микроданные ${ }^{1}$ двух волн обследования РПН. Репродуктивные намерения изучались на основе вопросов о желаемом и ожидаемом числе детей. Одинаковая формулировка вопросов в РПН-2012 и РПН-2017 позволила оценить значимые изменения в репродуктивных планах мужчин и женщин за период между двумя волнами обследования. Мотивы рождения еще одного ребенка и факторы откладывания рождения ребенка были изучены на данных обследования РПН-2017.

\footnotetext{
${ }^{1}$ Строго говоря, речь идет не о микроданных, а об агрегированных данных, размещенных на сервере Росстата с возможностью построения настраиваемых таблиц. Это, в свою очередь, наложило определенные ограничения на используемые методы анализа данных.
} 
В дополнение к количественным оценкам были проанализированы результаты фокус-групп с женщинами репродуктивного возраста, имеющими и не имеющими детей, на тему «Установки и модели репродуктивного поведения» ${ }^{2}$. Фокус-групповые дискуссии (ФГД) были проведены в 9 населенных пунктах с разной численностью/статусом и разным уровнем рождаемости: в городах Москве (город-миллионник), Воронеже (областной центр с низким уровнем рождаемости), Нижнем Новгороде (областной центр со средним уровнем рождаемости), Екатеринбурге (центр в регионе с высоким уровнем рождаемости), Тосно Ленинградской области (районный центр с низким уровнем рождаемости), Калачинск Омской области (районный центр со средним уровнем рождаемости), а также в пос. Рождественском и с. Дедилово Тульской области (сельская местность с низким уровнем рождаемости) и с. Белозерки Самарской области (сельская местность со средним уровнем рождаемости). В ФГД приняли участие женщины в возрасте от 20 до 44 лет, состоящие в отношениях с партнером, которые они считают постоянными, желающие и не желающие иметь больше детей, чем у них есть, с уровнем дохода от низкого до средневысокого. Было организовано 59 фокус-групп по 6 человек в каждой. Таким образом, общее число участников составило 354 человека.

В ходе исследования было выделено несколько подтипов целевой аудитории в зависимости от числа уже имеющихся детей, возраста, наличия или отсутствия высшего образования $(\mathrm{BO})$ :

- нет детей, 20-24 года, без ВО;

- $\quad$ нет детей, 21-24 года, ВО;

- $\quad$ нет детей, 25-34 года, ВО;

- 1 ребенок, 20-24 года, без ВО;

- 1 ребенок, 21-24 года, ВО;

- 1 ребенок, 25-34 года, ВО/без ВО;

- 1 ребенок, 35-44 года, ВО;

- 2 детей, 20-29 лет, без ВО;

- 2 детей, 21-34 года, ВО;

- 2 детей, 30-44 года, без ВО;

- 2 детей, 35-44 года, ВО;

- 3 детей, 20-29 лет, ВО/без ВО.

\section{РЕПРОДУКТИВНЫЕ УСТАНОВКИ РОССИЯН}

Для определения социальной нормы относительно «рекомендуемого» размера российской семьи был использован показатель среднего желаемого числа детей, а в качестве индикатора реального «репродуктивного климата» в стране - показатель среднего ожидаемого числа детей. В таблицах 1 и 2 представлены результаты сравнения РПН-2012 и РПН-2017 по среднему желаемому и ожидаемому числу детей у женщин и мужчин в различных возрастных группах. Средние значения показателя желаемого числа детей слабо

\footnotetext{
${ }^{2}$ Исследование было проведено компанией VALIDATA по заказу НИУ ВШЭ в 2017 г.
} 
варьировались по возрасту у женщин и мужчин в 2012 г., тогда как в 2017 г. возрастные различия стали более заметными, демонстрируя обратную U-образную зависимость: наиболее высокие оценки имеют женщины в возрасте 25-34 года и мужчины в возрасте 30-39 лет, более низкие оценки характерны для самых молодых (женщины до 25 лет, мужчины до 29 лет) и самых старших (старше 40 лет) родительских возрастов. Наибольшие гендерные различия в показателях также наблюдаются у младших и старших когорт. В средних же значениях ожидаемого числа детей можно обнаружить линейную зависимость (с небольшими отклонениями в более молодых возрастных группах): с возрастом ожидаемое число детей у женщин и мужчин уменьшается.

Таблица 1. Среднее желаемое и ожидаемое число детей у женщин разных возрастных групіп в 2012 и 2017 гг.

\begin{tabular}{|c|c|c|c|c|c|c|}
\hline \multirow[b]{2}{*}{ Возраст } & \multicolumn{2}{|c|}{$\begin{array}{c}\text { Желаемое число } \\
\text { детей }\end{array}$} & \multicolumn{2}{|c|}{$\begin{array}{c}\text { Ожидаемое число } \\
\text { детей }\end{array}$} & \multicolumn{2}{|c|}{ Разница в оценках } \\
\hline & $\begin{array}{c}2012 \\
(1)\end{array}$ & $\begin{array}{c}2017 \\
(2)\end{array}$ & $\begin{array}{c}2012 \\
(3)\end{array}$ & $\begin{array}{c}2017 \\
(4)\end{array}$ & $\begin{array}{c}\text { по желаемому } \\
\text { числу детей: } \\
(2)-(1) \\
\end{array}$ & $\begin{array}{c}\text { по ожидаемому } \\
\text { числу детей: } \\
(4)-(3) \\
\end{array}$ \\
\hline до 25 лет & 2,21 & 2,03 & 1,93 & 2,00 & $-0,17$ & 0,08 \\
\hline 25-29 лет & 2,30 & 2,17 & 2,03 & 1,99 & $-0,13$ & $-0,04$ \\
\hline 30-34 лет & 2,34 & 2,29 & 2,07 & 2,01 & $-0,05$ & $-0,05$ \\
\hline 35-39 лет & 2,33 & 2,22 & 1,88 & 1,87 & $-0,11$ & $-0,01$ \\
\hline 40 лет и старше & 2,25 & 2,03 & 1,58 & 1,71 & $-0,23$ & 0,13 \\
\hline $\begin{array}{l}\text { Все женщины в } \\
\text { возрасте 18-44 года }\end{array}$ & 2,28 & 2,15 & 1,92 & 1,90 & $-0,13^{*}$ & $-0,02$ \\
\hline
\end{tabular}

Источник: Расчеты автора на основе данных РПН-2012 и РПН-2017.

Примечания:* - Различия значимы на уровне 5\%.

Для определения статистической значимости использовали двухвыборочный $t$-тест с различными дисперсиями.

Такая дифференциация по возрасту объясняется, во-первых, ослаблением репродуктивной функции с возрастом, во-вторых - последовательностью процесса принятия решения о рождении еще одного ребенка: оно повторно взвешивается и переоценивается после каждого рождения.

По сравнению с 2012 г. показатель среднего желаемого числа детей в 2017 г. значимо уменьшился - на 0,13 у женщин и на 0,16 у мужчин (таблицы 1,2$)$. Разница между средними значениями по желаемому и ожидаемому числу детей сократилась на 0,11 у женщин и 0,12 у мужчин. Значимых изменений в средних оценках ожидаемого числа детей у женщин и мужчин за пятилетний период не произошло. Наибольшая разница в средних значениях данного показателя наблюдалась у самой молодой возрастной когорты - женщин и мужчин до 25 лет, что, по-видимому, свидетельствует о тенденции к откладыванию рождений на более поздний срок.

Результаты фокус-групп подтверждают полученные результаты, свидетельствующие о том, что общие представления о «правильном» составе семьи остаются довольно стабильными - родители и двое детей:

«В основном все говорят, что двое [детей] достаточно» (30-44 года, без ВО, доход средненизкий, 2 детей. Москва); 
«Мне казалось, чем больше, тем лучше. А сейчас я понимаю, что детям надо уделять внимание, любовь, оптимально это двое детей» (35-44 года. ВО, доход средневысокий, 1 ребенок. Москва);

«Есть какой-то закон, что двоих детей нужно. Навязывание общества, может быть. И я пришла к мнению, что нужен второй ребенок. Я поняла, что хочу быть мамой двоих детей» (30-39 лет, ВО/без ВО, доход низкий, 2 детей. С. Белозерки, Тульская область);

«Двое - это комплект» (25-34 года, ВО, доход средневысокий, нет детей. Воронеж).

Таблица 2. Среднее желаемое и ожидаемое число детей у мужчин разных возрастных групп в 2012 и 2017 гг.

\begin{tabular}{l|c|c|c|c|c|c}
\hline \multirow{2}{*}{ Возраст } & \multicolumn{2}{|c|}{$\begin{array}{c}\text { Желаемое число } \\
\text { детей }\end{array}$} & \multicolumn{2}{c|}{$\begin{array}{c}\text { Ожидаемое число } \\
\text { детей }\end{array}$} & \multicolumn{2}{c}{ Разница в оценках } \\
\cline { 2 - 7 } & $\begin{array}{c}2012 \\
(1)\end{array}$ & $\begin{array}{c}2017 \\
(2)\end{array}$ & $\begin{array}{c}2012 \\
(3)\end{array}$ & $\begin{array}{c}2017 \\
(4)\end{array}$ & $\begin{array}{c}\text { по желаемому } \\
\text { числу детей: } \\
(2)-(1)\end{array}$ & $\begin{array}{c}\text { по ожидаемому } \\
\text { числу детей: } \\
(4)-(3)\end{array}$ \\
\hline до 25 лет & 2,14 & 1,94 & 1,93 & 1,85 & $-0,20$ & $-0,09$ \\
$25-29$ лет & 2,30 & 2,13 & 2,02 & 1,99 & $-0,17$ & $-0,03$ \\
$30-34$ лет & 2,38 & 2,25 & 2,08 & 2,05 & $-0,13$ & $-0,04$ \\
35-39 лет & 2,38 & 2,25 & 1,99 & 2,00 & $-0,14$ & 0,02 \\
40 лет и старше & 2,31 & 2,15 & 1,82 & 1,78 & $-0,16$ & $-0,05$ \\
Все мужчины в & 2,30 & 2,14 & 1,97 & 1,93 & $-0,16 * *$ & $-0,04$ \\
возрасте 18-60 лет & &
\end{tabular}

Источник: Расчеты автора на основе данных РПН-2012 и РПН-2017.

Примечания: ** - Различия значимы на уровне $10 \%$.

Для определения статистической значимости использовался двухвыборочный t-тест с различными дисперсиями.

Независимо от возраста, уровня образования и дохода, идеальным вариантом для большинства женщин, не имеющих детей либо имеющих одного ребенка, считается рождение и воспитание двух разнополых детей:

«В основном все хотят двоих разнополых детей» (20-29 лет, ВО/без ВО, доход низкий, 1 ребенок. Пос. Рождественский, Тульская область);

«Двоих, желательно разнополых» (30-44 года, ВО/без ВО, доход средний, 1 ребенок. Екатеринбург);

«Двоих, мальчик и девочка» (25-34 года. ВО, доход средневысокий, без детей. Москва);

«Тоже двое: мальчик и девочка» (25-34 года, ВО, доход средневысокий, нет детей. Нижний Новгород).

Объяснений тому несколько:

«Мальчика рожаешь для мужа, а дочку рожаешь для себя» (35-44 года, ВО, доход средневысокий, 1 ребенок. Воронеж);

«Мне кажется, интереснее, когда и мальчик, и девочка» (20-29 лет, ВО/без ВО, доход средний, 1 ребенок. Екатеринбург). 
При этом восприятие «многодетности» и отношение к ней меняются в позитивную сторону: многодетность больше не ассоциируется напрямую с неблагополучными слоями населения, социальной дезадаптированностью. Третий ребенок представляется признаком благополучной и обеспеченной семьи:

«Мой молодой человек хочет семь, трое лучше для начала. Мой молодой человек один был в семье, но у него много двоюродных. Но он уже состоявшийся, у него машина, мы над этим работаем сейчас» (21-24 года, ВО, доход средневысокий, нет детей. Москва);

«Мы с мужем изначально планировали троих - надо только квартиру побольше, а так должны потянуть» (20-29 лет, ВО, средний доход, 2 детей, Москва);

«...чем больше, тем лучше, если есть финансовая возможность» (30-44 года, ВО/ без ВО, доход средний, 2 детей. С. Тосно, Ленинградская область);

«Если позволяют финансы, можно и троих, и десятерых рожать...» (20-29 лет, ВО/без ВО, доход низкий,1 ребенок. С. Белозерки, Самарская область);

«Конечно [хочется троих детей], живем раз в жизни, почему бы не родить. Здоровья и сил хватает, хорошо зарабатываем, сейчас ипотеку доплатим, будем думать об увеличении жилплощади» (30-44 года, ВО/без ВО, доход средний, 2 детей. Калачинск, Омская область).

Рождение третьего ребенка не вызывает ни вопросов, ни удивления, когда сами супруги/партнеры выросли в многодетной семье:

«...у нас традиция, у всех по трое детей, у папы два брата. Три нормально, но это предел» (35-44 года. ВО, доход средневысокий, 1 ребенок. Москва);

«Хотелось бы много [детей], я выросла в большой семье, понимаю, что это круто и здорово» (20-29 лет, ВО/без ВО, доход низкий, 1 ребенок. Пос. Рождественский, Тульская область);

«Вообще, хорошо бы троих. Весело в семье, много. Я вообще за семейные ценности, в доме должно быть много голосов, детей. Один это несерьезно» (25-34 года, ВО, доход средневысокий, нет детей. Воронеж);

«Я хочу троих, муж - пятерых. У его мамы пятеро детей, у его сестры пятеро, у старшего брата трое, сейчас четвертым беременна. А я хочу троих. Пять слишком много, с ума сойти» (20-29 лет, ВО/без ВО, доход низкий, 2 детей. С. Дедилово Тульская область).

\section{МОТИВЫ РОЖДЕНИЯ РЕБЕНКА}

На формирование репродуктивных намерений населения оказывают влияние два вида противодействующих друг другу факторов: мотивы, побуждающие к рождению ребенка, и факторы, сдерживающие рождение ребенка, т .е. влияющие на откладывание рождения детей. В таблице 3 представлены оценки женщинами и мужчинами значимости мотивов рождения второго и третьего ребенка. 


\section{Таблица 3. Значимость мотивов рождения второго и третьего ребенка для женщин и мужчин, \%}

\begin{tabular}{|c|c|c|c|c|}
\hline \multirow{2}{*}{ Мотивы рождения второго и третьего ребенка } & \multicolumn{2}{|c|}{ Второго } & \multicolumn{2}{|c|}{ Третьего } \\
\hline & женщины & мужчины & женщины & мужчины \\
\hline $\begin{array}{l}\text { Хотелось (хочется), чтобы имеющийся ребенок не } \\
\text { чувствовал себя одиноким }\end{array}$ & 68,7 & 62,5 & - & - \\
\hline $\begin{array}{l}\text { Желание супруга(и) / партнера(ши) иметь второго / } \\
\text { третьего ребенка }\end{array}$ & 58,1 & 61,5 & 48,4 & 48,5 \\
\hline $\begin{array}{l}\text { Хотелось (хочется), чтобы старший(ие) ребенок / дети } \\
\text { научился(лись) заботиться о младших }\end{array}$ & 54,8 & 51,0 & 54,0 & 50,0 \\
\hline $\begin{array}{l}\text { С двумя / тремя детьми больше гарантий, что } \\
\text { получишь от детей поддержку в старости, не } \\
\text { останешься одиноким }\end{array}$ & 49,1 & 47,9 & 49,9 & 46,3 \\
\hline Желание укрепить семью & 48,6 & 49,9 & 46,6 & 44,3 \\
\hline $\begin{array}{l}\text { Хотелось (хочется) снова иметь в семье маленького } \\
\text { ребенка }\end{array}$ & 44,4 & 37,4 & 47,3 & 41,5 \\
\hline $\begin{array}{l}\text { Желание решить жилищные проблемы, используя } \\
\text { государственную поддержку (например, } \\
\text { «материнский (семейный) капитал», бесплатное } \\
\text { предоставление земельного участка) }\end{array}$ & 42,1 & 36,1 & 43,9 & 37,0 \\
\hline Первый ребенок очень хотел (хочет) брата или сестру & 39,2 & 37,6 & - & - \\
\hline $\begin{array}{l}\text { У моих родителей или у родителей супруга(и) / } \\
\text { партнера(ши) было двое / трое детей }\end{array}$ & 38,0 & 36,7 & 23,6 & 22,6 \\
\hline Повышение уровня жизни семьи & 34,9 & 32,8 & 36,0 & 33,7 \\
\hline $\begin{array}{l}\text { Двое / трое детей повышают авторитет человека в } \\
\text { обществе }\end{array}$ & 26,2 & 27,6 & 25,3 & 26,6 \\
\hline $\begin{array}{l}\text { Второго / третьего ребенка иметь не собирались, но } \\
\text { когда случилась беременность, решил(а) / (решили) не } \\
\text { делать аборт }\end{array}$ & 22,4 & 21,8 & 25,1 & 23,5 \\
\hline $\begin{array}{l}\text { Мы не ограничиваем число детей в семье, их должно } \\
\text { быть столько, сколько Бог даст }\end{array}$ & 22,0 & 21,9 & 27,5 & 28,1 \\
\hline $\begin{array}{l}\text { У многих друзей, знакомых двое / трое детей, мне } \\
\text { (нам) не хотелось (не хочется) от них отставать }\end{array}$ & 18,7 & 18,4 & 12,5 & 12,2 \\
\hline $\begin{array}{l}\text { Желание иметь ребенка другого пола, если первые } \\
\text { двое детей одного пола }\end{array}$ & - & - & 46,8 & 44,4 \\
\hline $\begin{array}{l}\text { Семьи с тремя и более детьми имеют значительную } \\
\text { материальную помощь от государства }\end{array}$ & - & - & 40,4 & 34,0 \\
\hline $\begin{array}{l}\text { На третьего ребенка предоставляется ежемесячная } \\
\text { денежная выплата в размере прожиточного минимума } \\
\text { ребенка до достижения им возраста трех лет }\end{array}$ & - & - & 40,2 & 33,2 \\
\hline $\begin{array}{l}\text { Трое детей в будущем смогут больше помогать по } \\
\text { дому, в подсобном хозяйстве }\end{array}$ & - & - & 39,5 & 38,8 \\
\hline
\end{tabular}

Источник: Расчеты автора на основе РПН-2017.

Примечания: Респондентам необходимо было отметить по каждой строке степень влияния, где 2 «не повлияло», а 5 - «очень сильно повлияло». В таблице представлены \% выбравших варианты ответов «повлияло», «сильно повлияло» и «очень сильно повлияло».

Вопрос задавали женщинам и мужчинам, которые в блоке о желаемом либо ожидаемом числе детей указали 2 и более / 3 и более.

Результаты ранжированы по значимости мотивов рождения второго ребенка для женщин.

Прочерк-вопрос не задавался.

В качестве основного мотива для рождения второго ребенка часто указывают желание родителей избежать чувства одиночества у их ребенка. Зачастую, если женщины или их партнеры/супруги были единственным ребенком в родительской семье, то, 
вспоминая свои личные переживания, будущие родители хотят, чтобы их ребенок не чувствовал себя одиноким:

«Я всегда хотела сестру, а мама сделала аборт. Я жалею. Поэтому хочу, как минимум, двоих...» (25-34 года, без ВО, средний доход, 2 детей, Москва);

«...мы единственные были в семье, один ребенок вырастает эгоистом, надо еще одного обязательно» (25-34 года, ВО, доход средневысокий, 1 ребенок. Нижний Новгород);

«Я хочу двоих детей, просила у родителей братика или сестренку - мне не подарили. Поэтому я решила, что точно будут двое - про третьего подумаю» (20-24 года, без ВО, средненизкий доход, 1 ребенок. Воронеж);

«Я одна, у меня не было братьев и сестер, хотела, чтобы было два брата, мечтала девочку на руках носить» (20-29 лет, ВО/без ВО, доход низкий, 2 детей. С. Белозерки, Самарская область).

Основной мотив для рождения третьего ребенка - желание родителей, чтобы их старшие дети научились заботиться о младших. Высокую значимость данный мотив имеет и при рождении второго ребенка, так как родители опасаются, что их ребенок может вырасти эгоистом:

«...не хочу, чтобы дочка эгоисткой росла, вообще, спокойнее, когда у тебя двое детей» (35-44 года. ВО, доход средневысокий, 1 ребенок. Москва);

«У меня программа висела - мальчик и девочка. На второго дедушка подтолкнул сказал один ребенок будет эгоистом...» (30-44 года, без ВО, средний доход, 2 детей. Москва).

Не менее значимым мотивом для рождения как второго, так и третьего ребенка является желание супруга(и)/партнера иметь еще одного ребенка другого пола, что также подтверждается участницами фокус-групп:

«Хотелось сына для папы, брата для дочки» (30-39 лет, ВО/без ВО, доход низкий, 2 детей. С. Белозерки, Самарская область);

«Двоих [планировали]. У меня до последнего была надежда, что девочка и мальчик У меня, а родились две девочки, решили третьего, мужу ведь надо» (20-29 лет, ВО/без ВО, доход средний, 3 детей. Калачинск, Омская область).

Немаловажным мотивом для рождения большего числа детей служат своеобразные «гарантии» поддержки от детей в старости, подкрепленные опытом своих родителей:

«...многодетной матери тем хорошо, что та девочка позвонит, та позвонит, они соберутся. Они становятся, как маленькая семья, маленькая республика» (30-39 лет, ВО/без ВО, доход низкий, 2 детей. С. Белозерки, Самарская область).

Во многих семьях рождение еще одного ребенка оказывает укрепляющее воздействие на семью. Неспроста при заключении нового брака супруги часто решают завести еще одного (общего) ребенка: 
«...все мужчины хотят совместных детей» (30-39 лет, ВО/без ВО, доход низкий, 2 детей. С. Дедилово, Тульская обл.);

«Я думала, что будет только один [ребенок], прожила 6 лет со вторым мужем, получился еще один» (30-39 лет, ВО/без ВО, доход низкий, 2 детей. С. Белозерки, Самарская область).

Появление в семье маленького ребенка - это большая радость для родителей, особенно, когда старшие дети уже выросли:

«Он вырастет, будет большой, захочется еще ребеночка» (20-29, ВО/без ВО, доход средний, 1 ребенок. Екатеринбург).

Желание первого ребенка иметь брата или сестру также учитывается родителями при рождении второго ребенка:

«24 года, дочке 2 и 10, в будущем планируем еще ребенка, дочка просит» (20-29 лет, ВО/без ВО, доход низкий, 1 ребенок. С. Дедилово, Тульская область);

«...Я и для сына хотела братика или сестру, он тоже просит» (30-39, ВО/без ВО, доход низкий, 1 ребенок. С. Белозерки, Самарская область).

При этом, если у родителей женщины было больше двух детей, то это тоже является одним из мотивов рождения еще одного ребенка:

«У меня две сестры, я не представляю, как это быть одной в семье» (21-24 года, ВО, доход средневысокий, нет детей. Москва);

«Я после первого останавливаться не стала. Мальчик еще нужен. У нас у отца так заведено, что две девочки и мальчик. И надо же кому-то бизнес передать» (30-44 года, без ВО, средненизкий доход, 2 детей. Воронеж).

При планировании рождения еще одного ребенка родители также оценивают свои материальные возможности, и поддержка со стороны государства в этом случае играет немаловажную роль, особенно в случае рождения третьего ребенка (таблица 3 ).

Обращает на себя внимание тот факт, что появлению очередного ребенка в семье не всегда предшествует обдуманное мотивированное решение: нередко респонденты рассуждают о рождении детей, как о «даре свыше»:

«Если Бог даст, будет и семеро, я против абортов и бросания детей. Но я думаю, что будет один, хотя у меня есть сестра, я ее очень люблю, мы друг за друга горой» (20-24, без ВО, доход средний, нет детей. С. Тосно, Ленинградская область);

«Если Бог даст, я ни одного аборта не делала, оставлю» (30-39, ВО/без ВО, доход низкий, 2 детей. С. Дедилово, Тульская область);

«Последнего как рожала, пока больше не хочу, Бог даст, будет третий» (30-44, ВО/без ВО, доход средний, 2 детей. Калачинск, Омская область); 
«У русских поговорка: «Бог дал ребенка, Бог даст и на ребенка». По себе могу

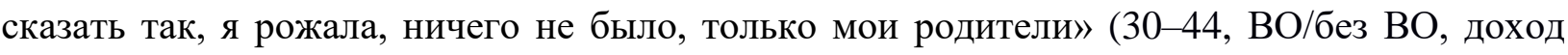
средний, 1 ребенок. Екатеринбург);

«Как Бог даст. Если будет, будет» (20-29 лет, ВО/без ВО, доход низкий,1-2 ребенка. С. Белозерки, Самарская область);

«Если Бог даст, не буду отказываться. И в 45 родим, что делать» (35-44, ВО, доход средневысокий, 1 ребенок. Воронеж).

Однако нельзя не учитывать значимость еще одного мотива для рождения большего числа детей: это сильное желание женщины иметь ребенка от «своего» мужчины. Количественные исследования не могут его выявить, в то время как в качественных исследованиях он отмечается:

«Нельзя захотеть ребенка просто так, ниоткуда. Появляется мужчина в твоей жизни, и ты именно конкретно от этого человека хочешь...» (25-34 лет, ВО, средневысокий, нет детей. Воронеж);

«... я всю голову ему [мужу] забила, хочу-хочу бэбика, на мозги капала-капала. Теперь девочку, чтобы не скучно» (21-24 года, ВО, средневысокий, 2 детей. Воронеж).

\section{СДЕРЖИВАЮЩИЕ ФАКТОРЫ РОЖДЕНИЯ РЕБЕНКА}

Сдерживающие факторы или факторы откладывания рождения ребенка, на которые указывают участники опросов и фокус-групп, можно разделить на социальноэкономические, связанные с благосостоянием семьи, ее материальными и социальными возможностями, и социально-психологические, связанные с представлениями о семейных и родительских ролях и жизненных этапах.

При принятии решения о рождении ребенка российские женщины и мужчины, как видно из таблицы 4, учитывают разные факторы, среди которых преобладают социальноэкономические.

Подтверждают и приоритет факторов, связанных с благосостоянием семьи, ее материальными, социальными возможностями, жилищной обеспеченностью, причем как для бездетных, так и имеющих детей, и результаты фокус-групповых дискуссий:

«Мы живем на съемной квартире, пока не построится дом. Это главная причина, что скоро детей не будет» (20-24 года, студентка, доход средний, нет детей. Тосно, Ленинградская область);

«Хочется пока встать на ноги в плане материальном» (25-34 года, ВО, доход средневысокий, нет детей. Нижний Новгород);

«У гражданского мужа не очень большой заработок, а у нас еще ипотека, хочется сначала ее выплатить, потом беременеть» (35-44 года, ВО, доход средневысокий, 1 ребенок. Москва); 
«Мне хотелось рожать второго, но у нас ипотека была, он сказал, я не смогу, не потяну» (35-44 года, ВО, доход средневысокий, 1 ребенок. Воронеж);

«У меня от денег зависит, если первые двое будут хорошо пристроены, бюджет будет позволять, тогда третьего» (20-29 лет, ВО/без ВО, доход средний, 1 ребенок. Екатеринбург);

«Если еще одного. В наше время сейчас сами видите, стоимость одежды, питания, коммунальные, сейчас садики и школы, все платное, садик стоит 2000, если месяц ходить. И жилплощадь надо увеличить, я не хочу, чтобы они в одной комнате ютились» (30-44 года, ВО/без ВО, доход средний, 2 детей. Калачинск, Омская область);

«Нет, не потяну по финансам. Это очень дорогое удовольствие. Дети подрастают, сейчас учеба платная будет, куда там третьего» (30-39 лет, ВО/без ВО, доход низкий, 2 детей. С. Дедилово, Тульская область);

«Изначально планировали с мужем троих, сначала всех подряд хотела, но у нас сейчас с жильем проблема, наша квартира маленькая для троих детей» (20-29 лет, без ВО, доход средненизкий, 2 детей. Москва).

Что касается социально-психологических факторов, то наиболее важными для российских женщин и мужчин являются желание пожить для себя и отсутствие партнеров/супругов. Наибольшие гендерные различия в оценках степени влиянии социально-психологическим факторов на откладывание рождения наблюдаются в желании супруга(и) подождать с рождением ребенка, в неуверенности женщин и мужчин относительно прочности брака/партнерства (таблица 4). Так, в первом случае оценки выше у мужчин, чем у женщин, а во втором случае - наоборот.

Согласно полученным результатам фокус-групп, социально-психологические барьеры у женщин варьируются в зависимости от наличия детей. Барьеры для рождения первого ребенка часто основаны на ощущениях неготовности к появлению детей в семье (и материальной, и психологической), неуверенности в партнерских отношениях:

«Не чувствую уверенности в себе. Как-то внутренне не готова пока назвать себя мамой. Не ощущаю поддержки со стороны мужа, чтобы он говорил: «Хочу, давай». Хочется пока встать на ноги в плане материальном» (25-34 года, ВО, доход средневысокий, нет детей. Нижний Новгород).

«Мне кажется, сложно одного поднять. Воспитать, материальная часть очень важна. Квартиру оставить, чтобы он не с нами жил. Душевная и материальная часть. Для меня кажется сложновато воспитать целого человека...» (25-34 года, ВО, доход средневысокий, нет детей. Москва).

Барьеры для рождения второго и третьего ребенка более конкретные и прагматичные, основанные на опыте воспитания и ухода за старшим ребенком (детьми):

«...Для меня долгожданный ребенок, тяжелый ребенок, беременность, роды тяжелые, на второго не решусь» (20-29 лет, ВО/без ВО, доход низкий, 1 ребенок. с. Белозерки, Самарская область). 
«Времени не хватает. Каждому ребенку надо уделять время... Одному уделяешь время, второму, сколько остается, а третьему тем более» (30-44 года, без ВО, доход средненизкий, 2 детей. Нижний Новгород).

\section{Таблица 4. Факторы откладывания рождения ребенка}

\begin{tabular}{|c|c|c|}
\hline Факторы, влияющие на откладывание рождения детей & Женщины & Мужчины \\
\hline Пока не позволяют материальные возможности & 73,4 & 70,2 \\
\hline Необходимо найти более высоко оплачиваемую работу & 65,8 & 69,4 \\
\hline Жилищные трудности, отсутствие собственного жилья & 57,9 & 55,9 \\
\hline Хочется хоть какое-то время пожить для себя & 48,9 & 51,4 \\
\hline Отсутствие супруга(ги) / партнера(ши) & 48,7 & 48,2 \\
\hline $\begin{array}{l}\text { Мне (супругу(е) / партнеру(ше)) трудно совмещать работу и уход за } \\
\text { ребенком }\end{array}$ & 36,2 & 33,1 \\
\hline Муж (жена) пока хочет подождать с рождением ребенка & 35,5 & 41,8 \\
\hline Не уверен(а) в прочности брака / партнерства & 32,2 & 27,1 \\
\hline $\begin{array}{l}\text { Необходимость выплачивать кредиты, которые не позволяют мне } \\
\text { супругу(е) / партнеру(ше) хотя бы на время оставить работу }\end{array}$ & 31,3 & 30,4 \\
\hline Трудно устроить ребенка в дошкольную образовательную организацию & 29,5 & 26,3 \\
\hline $\begin{array}{l}\text { Нет надежды на то, что родственники смогут оказывать регулярную } \\
\text { помощь в уходе за ребенком (или родственников нет) }\end{array}$ & 29,0 & 23,9 \\
\hline Нет твердой уверенности в том, что мне / нам нужен еще ребенок & 28,7 & 29,0 \\
\hline Младший ребенок пока слишком маленький & 27,7 & 24,1 \\
\hline Нужно закончить образование & 27,1 & 21,1 \\
\hline $\begin{array}{l}\text { Не хочу (супруг(а) / партнер(ша) не хочет) оставлять работу хотя бы на } \\
\text { время, стремлюсь (он / она стремится) к карьерному росту }\end{array}$ & 26,7 & 27,0 \\
\hline $\begin{array}{l}\text { Там, где я живу, нет благоприятных условий, облегчающих уход за } \\
\text { ребенком (мало хороших магазинов, плохо развито медицинское и } \\
\text { бытовое обслуживание, нерегулярно работает транспорт и т.д.) }\end{array}$ & 23,6 & 22,2 \\
\hline Пока не позволяет состояние здоровья супруга(ги) / партнера(ши) & 11,0 & 11,4 \\
\hline
\end{tabular}

Источник: Расчеты автора на основе РПН-2017.

Примечания: Респондентам необходимо было отметить по каждой строке степень влияния, где 2 «не влияет», а 5 - «очень сильно влияет». В табличе представлены \% выбравших варианты ответов «влияет», «сильно влияет» и «очень сильно влияет».

Вопрос задавали женщинам и мужчинам, которые на вопрос "Собираетесь ли Вы иметь ребенка (первого, если нет детей, или еще одного)? ответили «да, но позже, пока откладываю/ем».

Результаты ранжированы по наибольщему влиянию факторов для женщин.

Цветом выделены наиболее сильные расхождения в оценках мужчин и женщин.

Женщины, уже имеющие детей, более сознательно подходят к рождению еще одного, у них больше социально-психологических барьеров и сложностей. Они опасаются, что будут слишком уставать, что их будет «не хватать» морально и физически на двух или трех детей, одновременно им кажется проблемным совмещение занятости и воспитания:

«Во-первых, не готова морально. Еще поработать хочу, полгода, как работаю, с таким трудом вырвалась на работу. Я уже мечтала, когда смогу вырваться из дома, для меня сидеть дома это что-то неимоверное...» (20-29 лет, ВО/ без ВО, доход средний, 1 ребенок, Тосно, Ленинградская область);

«Если вдруг получится, ребенок родится, но психика моя не может представить, что у меня три ребенка, как у Анны Савушкиной, она в сад то за одним, то за вторым бегает, у 
нее самой психика не выдерживает, я видела ее состояние» (20-29 лет, ВО/без ВО, доход низкий, 2 детей. С. Дедилово, Тульская область).

Достаточно важным является комплекс барьеров, связанный с ожиданиями от партнера/супруга и его ролью, опасения, что он не вполне справится со своей главной обязанностью «обеспечивать семью» или не вполне «морально готов» быть отцом:

«Я мечтала пять лет о ребенке, но муж все нет» (20-29 лет, ВО/без ВО, доход низкий, 1 ребенок. С. Белозерки, Самарская область);

«Я готова была к рождению ребенка, пока мы жили в гражданском браке, а муж пока не созрел, хотя мы одного возраста» (30-44 года, ВО/без ВО, доход средний, 1 ребенок. Екатеринбург);

«У меня муж еще к первому ребенку не [был] готов. Но сейчас такие мужчины пошли, что ждать от них решения [родить] ребенка - будет демографический кризис, они не готовы к детям как таковым, особенно более одного, к двум. Редкий мужчина скажет, что он хочет пятерых, он готов» (30-44 года, без ВО, доход средневысокий, 2 детей. Нижний Новгород);

«Они [мужья] считают, что детей нужно воспитать, дать то и то, я согласна с этим. И троих перебор, двоих бы на ноги поставить, на троих не хватит уже» (20-29 лет, без ВО, доход средненизкий, 2 детей. Москва).

Негативное влияние на реализацию репродуктивных намерений российских женщин и мужчин может оказать такой фактор, как отсутствие помощи и поддержки со стороны родственников, в первую очередь - родителей:

«...постоянно упрашивать кого-то посидеть, бабушку и дедушку, все это классно, они любят внуков, но сейчас такое поколение бабушек и дедушек, что они хотят жить для себя, если рожаете, рожайте для себя. И в выходные в обязаловку посидеть мало кто захочет» (20-24 лет, студентка, доход средний, нет детей. Тосно, Ленинградская область).

Это подтверждают и количественные оценки: практически для каждой третьей женщины и каждого четвертого мужчины то, что родственники не могут оказывать регулярную помощь в уходе за ребенком (или родственников нет), является значимым фактором откладывания рождения детей (таблица 4).

\section{ЗАКЛЮЧЕНИЕ}

На основании полученных количественных и качественных оценок можно говорить, что социальная норма относительно «правильного» размера российской семьи остается достаточно стабильной: в среднем женщины и мужчины желают иметь двух детей. Это в очередной раз подтверждает гипотезу, что двухдетность является общей нормой в развитых странах, в первую очередь европейских (Sobotka, Beaujouan 2014). Среднее ожидаемое число детей у российских женщин и мужчин тоже остается на уровне, близком к двум. При этом в обществе увеличивается поляризация между теми, кто намерен иметь только одного ребенка, и теми, кто хочет и планирует иметь большую (многодетную) 
семью. В первом случае аргументы приводятся в пользу качества отношений «родительребенок» и больших инвестиций (как материальных, так и духовных) в человеческий капитал ребенка. Во втором случае - это большая дружная семья, семейные ценности и в будущем благополучная старость. Следует отметить, что результаты фокус-групп зафиксировали, по крайней мере, на вербальном уровне, позитивные изменения в восприятии многодетной семьи и отношении к ней: третий ребенок представляется признаком благополучной и обеспеченной семьи.

Главными мотивами для рождения большего числа детей является стремление родителей к тому, чтобы их дети не чувствовали себя одинокими и научились заботиться о младших (не выросли эгоистами), что обеспечивает, по мнению родителей, больше гарантий получения поддержки от детей в старости. Не менее важные мотивы - намерение респондентов укрепить семью и желание со стороны их супругов/партнеров иметь еще одного ребенка. Материальные возможности и поддержка со стороны государства также играют немаловажную роль при планировании рождения еще одного ребенка (особенно третьего).

На репродуктивные намерения российских женщин и мужчин, судя по их ответам, в первую очередь, оказывают влияние социально-экономические факторы, связанные с благосостоянием семьи, ее материальными и социальными возможностями, жилищной обеспеченностью. При этом необходимо учитывать, что решение о рождении ребенка принимают оба супруга/партнера, и если нет уверенности в прочности брака /партнерства, или хотя бы один из супругов/партнеров морально, физически либо материально не готов к появлению (еще одного) ребенка в семье, то это также становится важным фактором откладывания рождений.

\section{ЛИТЕРАТУРА}

Андреев Е.М., Бондарская Г.А. (2000). Можно ли использовать данные об ожидаемом числе детей в прогнозе численности населения? Вопросы статистики, 11, 56-62.

Антонов А.И. (2009). Падение рождаемости, кризис семьи и неизбежность депопуляции в Европе в первой половине XXI века (социологический подход). Демографические исследования, 6, 3-5.

Архангельский В. Н. (2006). Факторы рождаемости. М.: ТЕИС.

Архангельский В. Н. (2018). Рождаемость и репродуктивное поведение в России период активизации поддержки семей с детьми // Демографическая и семейная политика в контексте целей устойчивого развития. Сборник статей IX Уральского демографического форума, Том 1. Екатеринбург: Институт экономики УрО РАН, 7-25.

Белова В.А. (1975). Число детей в семье. М.: Статистика.

Бодрова В. (1997). Репродуктивные ориентации населения России. Мониторинг общественного мнения: экономические и социальные перемены, (3), 44-47.

Бодрова В. (1999). Репродуктивные установки россиян как барометр социальноэкономических процессов. Мониторинг общественного мнения: экономические и социальные перемены, 4 (42), 35-41. 
Борисов В.А. (1997). Желаемое число детей в российских семьях по данным микропереписи населения России 1994 года. Вестник Московского университета. Сочиология и политология, 18 (2), 29-64.

Выборочное наблюдение репродуктивных планов населения (2012). Федеральная служба государственной статистики. URL:

https://www.gks.ru/free_doc/new_site/RPN/Publisher/index.html (данные загружены 26.10.2019).

Выборочное наблюдение репродуктивных планов населения (2017). Федеральная служба государственной статистики. URL:

https://www.gks.ru/free_doc/new_site/RPN17/index.html (данные загружены 26.10.2019).

Головляницина Е.Б. (2007). Роль социально-психологических факторов в репродуктивных намерениях. В Т. М. Малева, О. В. Синявская (Ред.) Родители и дети, мужчины и женщины в семье и обществе, Вып. 1. М.: НИСП, 217-250.

Захаров С., Чурилова Е., Агаджанян В. (2016). Рождаемость в повторных союзах в России: позволяет ли вступление в новый супружеский союз достичь идеала двухдетной семьи? Демографическое обозрение, 3 (1), 35-51.

Захаров С. В., Вишневский А. Г., Сакевич В. И. (2006). Часть 3. Модернизация рождаемости. В А.Г. Вишневский (Ред.). Демографическая модернизация России, 1900-2000. М.: Новое издательство, 149-254.

Захаров С.В. (2012). Какой будет рождаемость в России? Демоскоn Weekly, 23, 495-497.

Землянова Е.В., Чумарина В.Ж. (2018). Откладывание деторождения российскими женщинами в современных социально-экономических условиях. Социальныле аспекты здоровья населения, 64(6). URL: http://vestnik.mednet.ru/content/view/1031/30/lang,ru/ (дата обращения 10.12.2019).

Райдер Н., Уэстоф Ч. (1971). Тенденции изменения ожидаемого числа детей в США: 1955, 1960, 1965 гг. В А.Г. Волков и Л.Е. Дарский (Ред.), Изучение мнений о величине семьи. М.: Статистика, 67-92.

Синявская О.В., Тындик А.О. (2009). Рождаемость в современной России: от планов к действиям? В Т. М. Малева, О. В. Синявская (Ред.) Родители и дети, мужчины и женщины в семье и обществе, Вып. 2. М.: НИСП, 9-44.

Тындик А.О. (2012). Репродуктивные установки и их реализация в современной России. Журнал исследований соџиальной политики, 10 (3), 361-376.

Фрейка Т., Захаров С. В. (2014). Эволюция рождаемости за последние полвека в России: оптика условных и реальных поколений. Демографическое обозрение, 1 (1), 106-143.

Balbo N., Billari F.C., Mills M. (2013). Fertility in advanced societies: A review of research. European Journal of Population/Revue européenne de Démographie, 29 (1), 1-38.

Bongaarts J. (2001). Fertility and reproductive preferences in post-transitional societies. Population and Development Review, 27, 260-281.

Caldwell J.C. (1982). Theory of Fertility Decline. London: Academic Press.

Coombs L.C. (1979). Reproductive goals and achieved fertility: A fifteen-year perspective. Demography, 16 (4), 523-534.

Iacovou M., Tavares L.P. (2011). Yearning, learning, and conceding: Reasons men and women change their childbearing intentions. Population and development review, 37 (1), 89-123. 
Jaffe D., Kogan L., Manor O., Gielchinsky Y., Dior U., Laufer N. (2015). Influence of late-age births on maternal longevity. Annals of epidemiology, 25 (6), 387-391.

Kohler H.-P. (2001). Fertility and Social Interactions: An Economic Perspective. Oxford: Oxford University Press.

Liefbroer A.C. (2009). Changes in family size intentions across young adulthood: A life-course perspective. European Journal of Population/Revue européenne de Démographie, 25 (4), 363-386.

McLanahan S. (2004). Diverging destinies: How children are faring under the second demographic transition. Demography, 41 (4), 607-627.

Morgan S.P. (1985). Individual and couple intentions for more children: A research note. Demography, 22 (1), 125-132.

Morgan S.P. (2001). Should fertility intentions inform fertility forecasts. In The Direction of Fertility in the United States (pp. 153-165). U.S. Census Bureau Conference.

Morgan S.P., Rackin H. (2010). The correspondence between fertility intentions and behavior in the United States. Population and Development Review, 36 (1), 91-118.

Mosher W.D., Jones J., Abma J.C. (2012). Intended and Unintended Births in the United States: 1982-2010. National Health Statistics Reports 55, July 2012.

Philipov D. (2009). Fertility intentions and outcomes: the role of policies to close the gap. European Journal of Population/Revue européenne de Démographie, 25 (4), 355.

Rindfuss R. R., Morgan S.P., Swicegood G. (1988). First Births in America: Changes in the Timing of Parenthood. Berkeley: University of California Press.

Selvaratnam T. (2014). The Big Lie: Motherhood, Feminism, and the Reality of the Biological Clock. Amherst, NY: Prometheus Books.

Sobotka T., Beaujouan É. (2014). Two Is best? The persistence of a two-child family ideal in Europe. Population and Development Review, 40 (3), 391-419.

Schmidt L., Sobotka T., Bentzen J.G., Nyboe Andersen A. (2011). Demographic and medical consequences of the postponement of parenthood. Human Reproduction Update, 18, (1), 2943.

van Peer C., Rabušic L. (2008). Will we Witness an Upturn in European Fertility in the Near Future? In People, Population Change and Policies (pp. 215-241). Springer, Dordrecht.

Voas D. (2003). Conflicting preferences: a reason fertility tends to be too high or too low. Population and Development Review, 29 (4), 627-646.

Westoff C.F. (1990). Reproductive intentions and fertility rates. International Family Planning Perspectives, 16 (3), 84-96.

Westoff C.F., Ryder N.B. (1977). The predictive validity of reproductive intentions. Demography, 14 (4), 431-453. 


\title{
FERTILITY INTENTIONS IN RUSSIA: MOTIVATION AND CONSTRAINTS
}

\section{$\underline{\text { TATIANA GUDKOVA }}$}

\begin{abstract}
This article examines the role of the various factors that influence the decision to have a child. The focus is on the reasons for deciding to have or not to have a (another) child and the socio-economic and sociopsychological factors influencing the postponement of childbearing.

A quantitative and qualitative assessment suggests that the desired family size in Russia remains relatively stable: women and men desire, on average, two children. The expected family size among Russian women and men also remains high, on average, nearly two children. The data of focus groups revealed an increasing polarization between those who intend to have only one child and those who intend to have a large family.

The study identified the main motivations to have another child-parents want their children not to feel lonely and to learn to care for the younger children. This provides, according to parents, more guarantees of support from children in old age. No less important are the intentions of men and women to strengthen their families and the desire of the spouse / partner to have another child. A family's economic and social capabilities and support from the government are essential in realizing fertility intentions. Socio-psychological factors, such as marital/ partnership instability and unwillingness of a spouse / partner to have a (another) child, have a key impact on the postponement of childbearing.
\end{abstract}

Key words: fertility, fertility intentions, expected family size, desired family size, large family, childbearing motivations, postponement of childbearing, Russia.

TAtiana Gudkova (tbgudkova@hse.ru), NATiOnal RESEARCH University Higher School of Economics, Russia.

THIS ARTICLE IS AN OUTPUT OF A RESEARCH PROJECT IMPLEMENTED AS PART OF THE BASIC RESEARCH PROGRAM AT THE

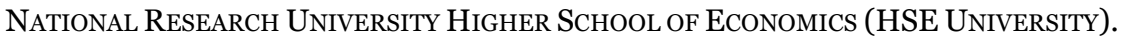

DATE RECEIVED : NOVEMBER 2019.

\section{REFERENCES}

Andreev E.M., Bondarskaya G.A. (2000). Mozhno li ispol'zovat' dannyye ob ozhidayemom chisle detey v prognoze chislennosti naseleniya? [Is it possible to use data on expected number of children at the population forecasting?]. Voprosy Statistiki, 11, 56-62. (In Russ.).

Antonov A.I. (2009). Padeniye rozhdayemosti, krizis sem'i i neizbezhnost' depopulyatsii v Evrope v pervoy polovine 21 veka (sotsiologicheskiy podkhod) [Fertility decline, family crisis, and inevitability of depopulation in Europe in the first half of the 21 st century (sociological approach)]. Demographic studies, 6, 3-5. (In Russ.).

Arkhangelskiy V.N. (2006). Faktory rozhdayemosti [Fertility factors]. M.: TEIS (In Russ.)

Arkhangelskiy V.N. (2018). Rozhdayemost' i reproduktivnoye povedeniye v Rossii period aktivizatsii podderzhki semey s det'mi [Fertility and reproductive behavior in Russia in the period of activating the support of families with children] // Demograficheskaya $i$ semeynaya politika $v$ kontekste tseley ustoychivogo razvitiya. Sbornik statey IX Ural'skogo demograficheskogo foruma, Vol. 1. Yekaterinburg: Institut ekonomiki UrO RAN (In Russ.)

Balbo N., Billari F.C., Mills M. (2013). Fertility in advanced societies: A review of research. European Journal of Population/Revue européenne de Démographie, 29 (1), 1-38. 
Belova V.A. (1975). Chislo detey v sem'ye [The number of children in the family]. M.: Statistika. (In Russ.).

Bodrova V. (1997). Reproduktivnyye oriyentatsii naseleniya Rossii [Reproductive orientations of Russia's Population]. Monitoring of public opinion: economic and social changes, (3), 4447. (In Russ.).

Bodrova V. (1999). Reproduktivnyye ustanovki rossiyan kak barometr sotsial'noekonomicheskikh protsessov [Reproductive attitudes of Russian citizens as a barometer of socio-economic processes]. Monitoring of public opinion: economic and social changes, 4 (42), 35-41. (In Russ.).

Bongaarts J. (2001). Fertility and reproductive preferences in post-transitional societies. Population and Development Review, 27, 260-281.

Borisov V.A. (1997). Zhelayemoye chislo detey v rossiyskikh sem'yakh po dannym mikroperepisi naseleniya Rossii 1994 goda [The desired number of children in Russian families on data microcensus 1994]. Vestnik Moskovskogo universiteta. Sotsiologiya i politologiya, 18 (2), 29-64. (In Russ.).

Caldwell J.C. (1982). Theory of Fertility Decline. London: Academic Press.

Coombs L.C. (1979). Reproductive goals and achieved fertility: A fifteen-year perspective. Demography, 16 (4), 523-534.

Frejka T., Zakharov S. (2014). Evolyutsiya rozhdayemosti v Rossii za polveka: optika uslovnykh i real'nykh pokoleniy [Fertility trends in Russia during the past half century: period and cohort perspectives]. Demographic Review, 1(1), 106-143. (In Russ.).

Golovlyanitsina E.B. (2007). Rol' sotsial'no-psikhologicheskikh faktorov v reproduktivnykh namereniyakh [The role of socio-psychological factors in reproductive intentions]. In T. M. Maleva, O. V. Sinyavskaya (Eds.) Roditeli i deti, muzhchiny i zhenshchiny v sem'ye i obshchestve [Parents and children, men and women in the family and society], Vol. 1. M.: NISP, 217-250. (In Russ.).

Iacovou M., Tavares L.P. (2011). Yearning, learning, and conceding: Reasons men and women change their childbearing intentions. Population and development review, 37 (1), 89-123.

Jaffe D., Kogan L., Manor O., Gielchinsky Y., Dior U., Laufer N. (2015). Influence of late-age births on maternal longevity. Annals of epidemiology, 25 (6), 387-391.

Kohler H.-P. (2001). Fertility and social interactions: An economic perspective. Oxford: Oxford University Press.

Liefbroer A.C. (2009). Changes in family size intentions across young adulthood: A life-course perspective. European Journal of Population/Revue européenne de Démographie, 25 (4), 363-386.

McLanahan S. (2004). Diverging destinies: How children are faring under the second demographic transition. Demography, 41 (4), 607-627.

Morgan S.P. (1985). Individual and couple intentions for more children: A research note. Demography, 22 (1), 125-132.

Morgan S.P. (2001). Should fertility intentions inform fertility forecasts. In The Direction of Fertility in the United States (pp. 153-165). U.S. Census Bureau Conference.

Morgan S.P., Rackin H. (2010). The correspondence between fertility intentions and behavior in the United States. Population and Development Review, 36 (1), 91-118. 
Mosher W.D., Jones J., Abma J.C. (2012). Intended and Unintended Births in the United States: 1982-2010. National Health Statistics Reports 55, July 2012.

Philipov D. (2009). Fertility intentions and outcomes: the role of policies to close the gap. European Journal of Population/Revue européenne de Démographie, 25 (4), 355.

Ryder, N.B., Westoff, C.F. (1967). The trend of expected parity in the United States: 1955, 1960, 1965. Population Index, 153-168.

Rindfuss R. R., Morgan S.P., Swicegood G. (1988). First Births in America: Changes in the Timing of Parenthood. Berkeley: University of California Press.

Schmidt L., Sobotka T., Bentzen J.G., Nyboe Andersen A. (2011). Demographic and medical consequences of the postponement of parenthood. Human Reproduction Update, 18, (1), 2943.

Selvaratnam T. (2014). The Big Lie: Motherhood, Feminism, and the Reality of the Biological Clock. Amherst, NY: Prometheus Books.

Sinyavskaya O.V., Tyndik A.O. (2009). Rozhdayemost' v sovremennoy Rossii: ot planov k deystviyam? In T.M. Maleva, O.V. Sinyavskaya (Eds.) Roditeli i deti, muzhchiny i zhenshchiny $\mathrm{v}$ sem'ye i obshchestve [Parents and children, men and women in the family and society], Vol. 2. M.: NISP, 9-44.

Sobotka T., Beaujouan É. (2014). Two Is best? The persistence of a two-child family ideal in Europe. Population and Development Review, 40 (3), 391-419.

Tyndik A.O. (2012). Reproduktivnyye ustanovki i ikh realizatsiya v sovremennoy Rossii [Reproductive attitudes and their realization in modern Russia]. The Journal of Social Policy Studies, 10 (3), 361-376.

van Peer C., Rabušic L. (2008). Will we Witness an Upturn in European Fertility in the Near Future? In People, Population Change and Policies (pp. 215-241). Springer, Dordrecht.

Voas D. (2003). Conflicting preferences: a reason fertility tends to be too high or too low. Population and Development Review, 29 (4), 627-646.

Vyborochnot nabludenit reproductivnykh planov naselenia (2012) [The sample survey of the reproductive plans of population]. Federalnaya sluzhba gosudarstvennoi statistiki. URL: https://www.gks.ru/free_doc/new_site/RPN/Publisher/index.html (data downloaded on 29.11.2019). (In Russ.).

Vyborochnot nabludenit reproductivnykh planov naselenia (2017) [The sample survey of the reproductive plans of population]. Federalnaya sluzhba gosudarstvennoi statistiki. URL: https://www.gks.ru/free_doc/new_site/RPN17/index.html_(data downloaded on 29.11.2019). (In Russ.).

Westoff C.F. (1990). Reproductive intentions and fertility rates. International Family Planning Perspectives, 16 (3), 84-96.

Westoff C.F., Ryder N.B. (1977). The predictive validity of reproductive intentions. Demography, 14 (4), 431-453.

Zakharov S., Churilova E., Agadjanian V. (2016). Rozhdayemost' v povtornykh soyuzakh v Rossii: pozvolyayet li vstupleniye v novyy supruzheskiy soyuz dostich' ideala dvukhdetnoy sem'i? [Fertility in higher-order marital unions in Russia: does a new partnership allow for the realization of the two-child ideal?]. Demographic Review, 3 (1), 35-51. (In Russ.).

Zakharov S.V., A.G. Vishnevsky, V.I. Sakevich (2006). Chast' 3. Modernizatsia rozhdaemosti [Part 3. Modernization of fertility] In A.G. Vishnevsky (ed.), Demograficheskaia 
modernizatsiia Rossii, 1900-2000 [Demographic modernization of Russia] (pp. 149-254). Moscow: Novoe izdatel'stvo. (In Russ.).

Zakharov S.V. (2012). Kakoy budet rozhdayemost' v Rossii? [What will be fertility in Russia?]. Demoscope weekly, 23, 495-497.

Zemlyanova E.V., Chumarina V.Zh. (2018). Otkladyvaniye detorozhdeniya rossiyskimi zhenshchinami v sovremennykh sotsial'no-ekonomicheskikh usloviyakh. [Births' postponement by women in Russia within modern socio-economic context]. Sotsial'nyye aspekty zdorov'ya naseleniya, 64(6). URL:

http://vestnik.mednet.ru/content/view/1031/30/lang,ru/ (accessed 10.12.2019). 